\title{
Observations on the nature and origin of lipids in the small intestine of the sheep
}

\author{
By AILEEN M. LENNOX, A. K. LOUGH and G. A. GARTON \\ Rowett Research Institute, Bucksburn, Aberdeen \\ (Received 14 September 1967-Accepted 18 October 1967)
}

\begin{abstract}
I. Total lipids were extracted from digesta obtained from the rumen, abomasum and upper small intestine (jejunum) of each of four slaughtered sheep. The lipids were fractionated into unesterified fatty acids, neutral lipids and phospholipids and the proportional contribution of each fraction to the total fatty acids was determined.

2. The contribution made by phospholipids to the total fatty acids in the digesta showed a marked increase in the samples from the small intestine compared with those from the rumen and abomasum. This increase was apparently due to the presence of biliary phospholipids.

3. 'Total lipids and conjugated bile acids were extracted from sheep bile, the lipids were fractionated and their fatty-acid composition was determined. Phospholipids predominated and these consisted mainly of phosphatidylcholine, together with some lysophosphatidylcholine.

4. Both phospholipids contained significant amounts of unsaturated $\mathrm{C}_{18}$ components which could account, at least in part, for the previously reported increment to the proportion of these acids in the digesta when it enters the upper jejunum.

5. The overall fatty acid compositions of the two biliary phospholipids were very similar and, in common with other naturally occurring phosphatidylcholines, the fatty acids present in position 2 of the phosphatidylcholine of bile were found to consist almost entirely of unsaturated components.

6. Total lipids and conjugated bile acids were extracted from samples of digesta obtained from three sheep with cannulas in different positions in the jejunum. Analysis of the lipids indicated that biliary phospholipids, in particular phosphatidylcholine, underwent progressive hydrolysis in the intestinal lumen.

7. The distribution of conjugated bile acids, unesterified fatty acids and phospholipids between the solid (particulate) and liquid (micellar) phases of the intestinal digesta was determined. These chyme constituents were, for the most part, associated with the particulate matter and thus, at any given time, it appears that only a small fraction of the total fatty acids is available for absorption in micellar form. It is suggested that the micellar solubilization of fatty acids may be facilitated by the presence of lysophosphatidylcholine.
\end{abstract}

Previous studies have shown that, in the rumen of the sheep, dietary lipids are subjected to extensive hydrolysis by bacteria, and unsaturated fatty acids can undergo partial or complete hydrogenation. Since the lipids of most common feeds (e.g. galactoglycerides of herbage, triglycerides of 'concentrates' of vegetable origin) have a high content of $\mathrm{C}_{18}$ unsaturated fatty acids, microbial activity results in the accumulation of free stearic acid (as the end-product of hydrogenation) and of geometrical (trans) and positional isomers of oleic, linoleic and linolenic acids as the products of incomplete hydrogenation. The hydrolysis of glyceridic lipids is complete and the liberated glycerol is fermented to short-chain, water-soluble fatty acids which are absorbed across the rumen wall. Very little, if any, degradation of long-chain fatty acids is thought to take place in the rumen and there is no evidence that acids of chain length $\mathrm{C}_{16}$ and greater are absorbed from the rumen. For recent reviews of lipid metabolism in the rumen see Garton (1965, 1967).

Thus, the lipids which are present in the digesta passing more or less continuously 
from the rumen through the abomasum to the small intestine consist largely of unesterified fatty acids, together with the structural lipids of the micro-organisms which accompany the digesta.

Feliński, Garton, Lough \& Phillipson (1964) noted that, compared with the lipids in the rumen contents of the sheep, the lipids in the lumen of the upper small intestine contained enhanced proportions of $\mathrm{C}_{18}$ unsaturated fatty acids in both unesterified and esterified form. It was therefore decided to investigate the source of these fatty acids and to study in more detail the nature of the lipids in the lumen contents of the small intestine. Some of the results of these investigations have been described in a brief preliminary communication (Lennox, Lough \& Garton, I965).

\section{EXPERIMENTAL}

\section{Source of alimentary tract contents}

Slaughtered sheep. Samples of digesta were obtained from each of two adult animals (sheep 1 and 2) as soon as possible after they had been given a lethal dose of Pentobarbitone sodium, BP (May and Baker) by intravenous injection and similarly from two others (sheep 3 and 4 ) which were killed by exsanguination following 'captivebolt' stunning. String ligatures were used to isolate portions of the alimentary tract before it was removed from the carcass to allow samples to be taken of the contents of the rumen, abomasum and upper small intestine (i.e. duodenum and proximal half of the jejunum). For several months before they were killed the sheep had received a diet of hay and 'concentrates' (linseed meal and crushed oats).

Cannulated sheep. Samples of digesta were collected from three animals (sheep 5, 6 and 7), each of which was fitted with a pair of 're-entrant' cannulas (Ash, 1962) in different parts of the jejunum, namely $0.5,2 \cdot 0$ and $8.0 \mathrm{~m}$ respectively distal to the point of entry of the common bile duct. From the proximal cannula of each pair the digesta was collected into a $100 \mathrm{ml}$ measuring cylinder which was kept at $c .90^{\circ}$ (in a bath of hot water) to inactivate lipolytic enzymes. A total of $300-500 \mathrm{ml}$ was thus collected over a period of several hours. During the collection a similar volume of an aqueous solution at $37^{\circ}$ ( $75 \mathrm{~mm}$ with respect to $\mathrm{NaCl}$ and $25 \mathrm{~mm}$ with respect to $\mathrm{KCl}$ ) was introduced, in small portions at a time, into the intestine via the adjacent (distal) cannula. About half way through the collection period a small sample of about $\mathrm{r} \circ \mathrm{ml}$ digesta was taken separately for measurement (by glass electrode) of its $\mathrm{pH}$ value. For several weeks before the samples were taken each sheep received a daily ration of $800 \mathrm{~g}$ of chopped dried grass.

\section{Source of bile}

The gall-bladders were removed from six adult sheep after they were killed at an Aberdeen slaughterhouse; the pooled bile (178 ml) was freeze-dried and stored in this condition at $\mathrm{I}^{\circ}$ for a few days before analysis was commenced.

\section{Analytical procedures}

Digesta from slaughtered sheep. Samples ( $100 \mathrm{~g}$ ) of the contents of the rumen, abomasum and upper small intestine were treated as described by Feliński et al. 
(1964) to extract and fractionate the constituent lipids and also to prepare the methyl esters of their component fatty acids. In this procedure methyl esters of unconjugated and chemically-deconjugated bile acids (which accompany the fatty acid methyl esters prepared from intestinal contents) are removed by selective adsorption on silicic acid. To ascertain the probable nature of the phospholipids which were isolated, small samples were examined by thin-layer chromatography (Wagner, Hörhammer \& Wolff, 1961).

Bile. Freeze-dried bile ( $\left.\mathrm{I}^{\circ} \circ \mathrm{g}\right)$, representing that derived from $100 \mathrm{ml}$ of fresh bile, was taken into solution in $75 \mathrm{ml}$ of distilled water and this was acidified with $5 \mathrm{ml}$ $\mathrm{N}-\mathrm{HCl}$. Based on the lipid extraction method of Bligh \& Dyer (1959), the acidified mixture of bile constituents was emulsified with $100 \mathrm{ml}$ of chloroform and $200 \mathrm{ml}$ of methanol in a mixer-emulsifier (Silverson Machines Ltd, London) for $30 \mathrm{sec}$; $100 \mathrm{ml}$ each of chloroform and distilled water were then added and the mixture (now biphasic) again treated for I min in the mixer. After centrifuging at $1400 \mathrm{~g}$ for $15 \mathrm{~min}$ the upper (aqueous methanolic) layer was removed by suction and the remaining interfacial solid matter and chloroform were separated by filtration through a pad of lipid-free cottonwool. The chloroform solution, which contained all the lipids and some of the bile acids, was taken to dryness in a stream of nitrogen on a warm water-bath and the residue weighed, giving $c .3 \circ \mathrm{g}$ material/100 $\mathrm{ml}$ bile. (The rest of the bile acids, present in the aqueous methanol, can be recovered, if required, by extraction with n-butanol.)

The lipids and accompanying bile acids were separated by chromatography on a column of silicic acid prepared as described by Garton \& Duncan (1957), except that chloroform was used to prepare the slurry (cf. Feliński et al. I964). The lipids plus bile acids were applied in solution in chloroform to the column, $\mathrm{r} \cdot \mathrm{Og}$ material $/ 3 \circ \mathrm{g}$ silicic acid being used. The column was then eluted successively with (I) chloroform to remove neutral lipids, unesterified fatty acids, unconjugated bile acids and pigments, (2) acetone-methanol (4:I, v/v) to remove conjugated bile acids, and (3) methanol to remove phospholipids. Further fractionation of the lipids eluted by chloroform was effected as outlined by Garton, Duncan \& Lough (196I) to yield unesterified fatty acids, cholesterol esters, triglycerides and free cholesterol; fatty acid methyl esters for gas-chromatographic analysis (see below) were prepared (Duncan \& Garton, 1962) from appropriate fractions. The phospholipids were fractionated on a silicic acid column (30 mg phospholipid/g silicic acid) with, as successive eluting solvents, chloroform-methanol $(4: \mathrm{I}, \mathrm{v} / \mathrm{v})$ for the elution of phosphatidylethanolamine, chloroform-methanol $(\mathrm{r}: \mathrm{r}, \mathrm{v} / \mathrm{v})$ to elute phosphatidylcholine (lecithin) followed by sphingomyelin, and finally methanol alone to remove lysophosphatidylcholine (lysolecithin). Methyl esters of the component fatty acids were prepared by direct methanolysis (Duncan \& Garton, 1962).

In all the above column chromatographic procedures each eluting solvent was used until no further lipid was removed from the column and the homogeneity of each fraction was checked by thin-layer chromatography; the adsorbent used was Kieselgel G (Merck A.-G., West Germany) and the appropriate solvents and 'spray' reagents were those recommended by Malins \& Mangold (I960) for lipids and by Hofmann (1964) for bile acids. Reference specimens of authentic lipids were prepared in this 
laboratory or obtained from Koch-Light Laboratories Ltd (Colnbrook, Bucks.) and reference samples of bile acids were obtained from Maybridge Chemical Co. Ltd (Tintagel, Cornwall).

Phospholipase A from Crotalus adamanteus venom (Koch-Light Laboratories Ltd, Colnbrook, Bucks.) was used according to Long \& Penny (I957) to release the fatty acids esterified in the $\beta$-position of $5^{8} \mathrm{mg}$ of phosphatidylcholine.

Digesta from cannulated sheep. The lipids and bile acids in a representative portion ( $100 \mathrm{ml}$ ) of digesta were extracted and fractionated in a manner similar to that described for bile. In order to obtain approximately the same proportions of chloroform, methanol and water as those recommended by Bligh \& Dyer (1959), the water content of the digesta was determined by drying a sample to constant weight in an oven at $\mathrm{I} 10^{\circ}$. The digesta was acidified to a $\mathrm{pH}$ value between $\mathrm{I} \cdot \mathrm{O}$ and 2.0 with $\mathrm{N}-\mathrm{HCl}$ before extraction and the water thus added taken into account before adding the appropriate volumes of chloroform and methanol. Following the removal of the aqueous methanol, the solid (inter-layer) matter, after separation from the chloroform, was re-extracted for $30 \mathrm{sec}$ in the mixer with $100 \mathrm{ml}$ of chloroform-methanol-water $(2: 2: \mathrm{I} \cdot 8, \mathrm{v} / \mathrm{v} / \mathrm{v})$ and the resulting chloroform layer combined with that obtained from the initial extraction.

To obtain the liquid (micellar) phase of the digesta a sample (roo ml) was centrifuged at $1400 \mathrm{~g}$ for $15 \mathrm{~min}$ to remove the main bulk of the solids. The supernatant solution was centrifuged for $\mathrm{I}_{2} \mathrm{~h}$ at $105000 \mathrm{~g}$ in an ultracentrifuge (Spinco, Model L), using a rotor which accommodated twelve cellulose nitrate tubes, each holding $13.5 \mathrm{ml}$ of liquid. The resulting clear fluid was decanted from the small plugs of solid matter and, following acidification, the lipids and bile acids were extracted and separated in the same way as described above for bile and whole digesta.

Fatty acids. The methyl esters of fatty acids were analysed, before and after hydrogenation, by gas-liquid chromatography as previously described (Duncan \& Garton, 1963). In the appropriate Tables the acids are designated by the shorthand nomenclature of Dole, James, Webb, Rizack \& Sturman (1959), which shows the number of carbon atoms/molecule, followed by the number of double bonds.

\section{RESULTS AND DISCUSSION}

\section{Alimentary tract contents from slaughtered sheep}

The results presented in Table I amplify the earlier findings of Feliński et al. (I964) by showing that the increased proportion of esterified fatty acids found in the lipids of the upper small intestine, as compared with those in the rumen lipids, is due almost entirely to an increment to the proportion of phospholipids present. Thin-layer chromatography of these phospholipids indicated that they consisted mainly of a mixture of phosphatidylcholine and lysophosphatidylcholine.

The fatty acid composition of each of the lipid fractions in the digesta samples from sheep 4 was determined, giving the values shown in Table 2; for clarity of presentation, the results for the abomasal lipids are not included since they were almost the same as those for rumen lipids. 
Previous observations have shown that, compared with rumen contents, enhanced proportions of $\mathrm{C}_{18}$ unsaturated fatty acids are present in the free fatty acids and, more markedly, in the esterified fatty acid fraction of the digesta in the small intestine of the sheep (Felinski et al. 1964; Ward, Scott \& Dawson, 1964; Leat, 1965) and the

Table I. Percentage proportions of the fatty acids contributed by the major lipid fractions to the total fatty acids of the digesta in different parts of the alimentary tract of four sheep which had received a diet of hay and vegetable concentrates

\begin{tabular}{|c|c|c|c|}
\hline \multirow[b]{2}{*}{ Source of digesta } & \multicolumn{3}{|c|}{ Source of fatty acids } \\
\hline & $\begin{array}{l}\text { Unesterified } \\
\text { fatty acids }\end{array}$ & $\begin{array}{l}\text { Neutral } \\
\text { lipids }\end{array}$ & Phospholipids \\
\hline \multicolumn{4}{|c|}{ Sheep I } \\
\hline Rumen & $7 I \cdot 5$ & $26 \cdot 2$ & $2 \cdot 3$ \\
\hline Abomasum & $70 \cdot 8$ & $27 \cdot 4$ & $\mathbf{1} \cdot 8$ \\
\hline Upper jejunum & $67 \cdot 4$ & I $7 \cdot 8$ & $14 \cdot 8$ \\
\hline \multicolumn{4}{|c|}{ Sheep 2} \\
\hline Rumen & $69 \cdot 1$ & $2 \mathrm{I} \cdot \mathrm{I}$ & $9 \cdot 8$ \\
\hline Abomasum & $75^{\circ} 0$ & 20.4 & $4 \cdot 6$ \\
\hline Upper jejunum & $50 \cdot 0$ & $24 \cdot 5$ & $25 \cdot 5$ \\
\hline \multicolumn{4}{|c|}{ Sheep 3} \\
\hline Rumen & $74 \cdot 8$ & $19 \cdot 7$ & $5 \cdot 5$ \\
\hline Abomasum & $8 I \cdot 7$ & 14.7 & $3 \cdot 6$ \\
\hline Upper jejunum & $46 \cdot 0$ & $20 \cdot 0$ & $34 \cdot 0$ \\
\hline \multicolumn{4}{|c|}{ Sheep 4} \\
\hline Rumen & 70.8 & $27 \cdot 2$ & $2 \cdot 0$ \\
\hline Abomasum & 80.9 & 16.2 & $2 \cdot 9$ \\
\hline Upper jejunum & 50.4 & $26 \cdot \mathrm{I}$ & $23 \cdot 5$ \\
\hline
\end{tabular}

Table 2. Proportions of palmitic acid (16:0) and $C_{18}$ fatty acids in the principal lipid components of digesta from the rumen and upper small intestine of sheep 4

(Values as \% by weight of total fatty acids in each class of lipid)

\begin{tabular}{|c|c|c|c|c|c|c|}
\hline \multirow{2}{*}{$\begin{array}{l}\text { Fatty } \\
\text { acid }\end{array}$} & \multicolumn{2}{|c|}{ Unesterified fatty acids } & \multicolumn{2}{|c|}{ Neutral lipids } & \multicolumn{2}{|c|}{ Phospholipids } \\
\hline & Rumen & Intestine & Rumen & Intestine & Rumen & Intestine \\
\hline I 6:0 & $10 \cdot 3$ & 142 & $3 I \cdot 0$ & $26 \cdot 5$ & 40.3 & $2 \mathrm{I}^{\circ} 5$ \\
\hline I 8:0 & $78 \cdot 0$ & $54 \cdot 9$ & $33 \cdot 4$ & $50 \cdot 2$ & 13.7 & $45 \cdot 7$ \\
\hline $18: 1$ & II 7 & 15.5 & $\mathrm{I} 7 \cdot \mathrm{I}$ & $9 \cdot \mathrm{I}$ & $8 \cdot 2$ & $16 \cdot 6$ \\
\hline $18: 2$ & Trace & $4 \cdot 0$ & $I \cdot 5$ & 0.8 & $6 \cdot 0$ & 6.8 \\
\hline I $8: 3$ & Trace & $4 \cdot 0$ & 3.5 & $2 \cdot 5$ & - & $3 \cdot 0$ \\
\hline
\end{tabular}

goat (McCarthy, 1962). The present investigation confirmed these findings with respect to unesterified fatty acids, and further showed (Table 2 ) that the increment to the esterified $\mathrm{C}_{18}$ unsaturated fatty acids was confined to the phospholipid fraction. Bile is evidently the source of these phospholipids, of which it was estimated by Adams $\&$ Heath ( 1963 ) that some IO-I5 g/day (almost all phosphatidylcholine and lysophos- 
phatidylcholine) enter the small intestine of the adult sheep; pancreatic juice contains virtually no lipid (Leat, 1965). As was found by Adams \& Heath (1963), Leat (1965) and by ourselves (Lennox et al. 1965; see also below), biliary phospholipids contain significant proportions of $\mathrm{C}_{18}$ unsaturated fatty acids, thus accounting in part, if not entirely, for the increment to the proportions of these acids observed in the lipids of the lumen contents of the small intestine.

Though bile contributes in small measure to the neutral lipids in the jejunum, these are probably largely derived from the lipids of the rumen bacteria and protozoa which are associated with the digesta passing down the alimentary tract.

Bile

In Table 3 are shown the amounts of the major classes of lipids found in the pooled sample of gall-bladder bile. This analysis is in general agreement with the values given

Table 3. Lipid constituents of the pooled gall-bladder bile from six adult sheep

\begin{tabular}{lc}
\multicolumn{1}{c}{ Lipid } & $\begin{array}{c}\text { Amount } \\
\text { (mg/I00 } \mathrm{ml} \\
\text { bile) }\end{array}$ \\
Unesterified fatty acids & 46 \\
Cholesterol esters & 31 \\
Cholesterol & 86 \\
Triglycerides & 37 \\
Phospholipids & \\
Phosphatidylethanolamine & 44 \\
Phosphatidylcholine & I 148 \\
Lysophosphatidylcholine & I 17
\end{tabular}

Details of the sampling procedure are given on p. 238 .

Table 4. Proportions of $C_{16}$ and $C_{18}$ fatty acids in the phospholipids and unesterified fatty acids of pooled bile from six adult sheep

(Values as \% by weight of total fatty acids* in each lipid)

\begin{tabular}{|c|c|c|c|c|}
\hline \multirow[b]{2}{*}{ Fatty acid } & \multicolumn{3}{|c|}{ Phospholipids } & \multirow[b]{2}{*}{$\begin{array}{l}\text { Unesterified } \\
\text { fatty acids }\end{array}$} \\
\hline & $\begin{array}{l}\text { Phosphatidyl- } \\
\text { choline }\end{array}$ & $\begin{array}{l}\text { Lysophos- } \\
\text { phatidyl- } \\
\text { choline }\end{array}$ & $\begin{array}{l}\text { Phosphatidyl- } \\
\text { ethanolamine }\end{array}$ & \\
\hline $\mathrm{r} 6: 0$ & $25 \cdot 7$ & $26 \cdot 3$ & $13 \cdot 8$ & $26 \cdot 4$ \\
\hline $16: I$ & $4 \cdot 8$ & $3 \cdot 9$ & 0.4 & $2 \cdot 2$ \\
\hline $18: 0$ & $9 \cdot I$ & $9 \cdot 6$ & $27 \cdot 8$ & $18 \cdot 5$ \\
\hline I8: I & $30 \cdot 7$ & $35^{\cdot} \cdot \mathrm{I}$ & $28 \cdot 9$ & $26 \cdot 6$ \\
\hline $18: 2$ & $6 \cdot 9$ & $6 \cdot 9$ & $5 \cdot 8$ & $12 \cdot 1$ \\
\hline $18: 3$ & $7 \cdot 4$ & $6 \cdot 2$ & $4 \cdot 3$ & $8 \cdot 7$ \\
\hline
\end{tabular}

Details of the sampling procedure are given on p. 238 .

* In each lipid small amounts of saturated and unsaturated acids having $12,14,15,17,20$ and 22 carbon atoms were also present.

by Leat (1965) for the amounts of unesterified fatty acids, cholesterol and total phospholipids in hepatic bile and with the observation of Adams \& Heath (1963) that phosphatidylcholine and lysophosphatidylcholine are the principal phospholipids present though, compared with our analysis, these workers found that lysophos- 
phatidylcholine constituted a greater proportion of the total phospholipids. Thinlayer chromatography indicated that only traces of sphingomyelin were present.

The composition of the phospholipids and of the unesterified fatty acids with respect to their content of $\mathrm{C}_{16}$ and $\mathrm{C}_{18}$ fatty acids is given in Table 4. The unesterified fatty acids and those of each of the three phospholipids contained similar proportions of $\mathrm{C}_{18}$ mono-, $\mathrm{di}$, and tri-unsaturated components; as Table 3 indicates, the greater part of the total $\mathrm{C}_{18}$ unsaturated acids in the bile was present in the form of phosphatidylcholine.

It is of interest to note that, as previously observed by Adams \& Heath (1963), the fatty acid compositions of the phosphatidylcholine and lysophosphatidylcholine are very similar. When the phosphatidylcholine was subjected to the action of phospholipase $A$ (which specifically removes fatty acids esterified to the secondary alcoholic group) it was found (Table 5) that, in common with most naturally occurring phosphatidylcholines, these acids were almost entirely unsaturated components. Though it is probable (cf. Van den Bosch \& Van Deenen, I965) that the lysophosphatidylcholine

Table 5. Proportions of $C_{16}$ and $C_{18}$ fatty acids in the $\beta$-position of bile phosphatidylcholine

(Values as $\%$ by weight of total fatty acids released by the action of phospholipase A)

\begin{tabular}{cr} 
Fatty acid & \multicolumn{1}{c}{$\%$} \\
$16: 0$ & $3 \cdot 9$ \\
$16: 1$ & $2 \cdot 7$ \\
$18: 0$ & 0.3 \\
$18: 1$ & $57 \cdot 2$ \\
$18: 2$ & 12.4 \\
$18: 3$ & $11 \cdot 7$
\end{tabular}

Details of the sampling procedure are given on p. 238 .

as it exists in bile is a mixture of $\beta$ and $\gamma$ forms (i.e. with the fatty acid esterified to the secondary or primary alcoholic group respectively), their relative proportions could not be determined in this investigation because chromatography on silicic acid is known to effect the isomerization of one form of lysophosphatidylcholine into the other (Slotboom, De Haas \& Van Deenen, 1963; De Haas \& Van Deenen, 1965).

\section{Intestinal contents from cannulated sheep}

The results of the analyses and $\mathrm{pH}$ measurements of the representative samples of small intestinal digesta obtained from sheep 5,6 and 7 are shown in Table 6. Whereas the values for the content of conjugated bile acids increase progressively with increasing distance of the cannula from the bile duct, the values for unesterified fatty acids and neutral lipids show no similar trend, suggesting that the former are absorbed from the jejunum and the latter are also absorbed or hydrolysed, or both. Evidence in support of this suggestion was obtained in subsequent experiments (Lennox \& Garton, I 968 ) in which the degree of concentration of digesta was determined during its passage through various portions of the small intestine.

The amounts of the two phospholipids show interesting differences; whereas in the 
upper jejunal sample from sheep 5 phosphatidylcholine was present in greater amount than lysophosphatidylcholine, the converse obtained in the sample of digesta taken from the more distal cannula of sheep 6 and, in the sample from the cannula of sheep 7 (some $6 \mathrm{~m}$ lower down the intestine), neither species of phospholipid was present. In vitro observations by Leat $(1965)$ showed that, when sheep bile and pancreatic juice were mixed, lysophosphatidylcholine and unesterified fatty acids were formed; our

\section{Table 6. Lipid composition and $p H$ of jejunal contents obtained from three cannulated sheep which had received a diet of chopped dried grass}

(Values as $\mathrm{mg} / 100 \mathrm{ml}$ digesta)

\begin{tabular}{|c|c|c|c|}
\hline \multirow[b]{2}{*}{ Constituent } & \multicolumn{3}{|c|}{$\begin{array}{l}\text { Distance }(\mathrm{m}) \text { of cannula } \\
\text { distal to bile duct }\end{array}$} \\
\hline & $\begin{array}{c}0.5 \\
\text { (sheep 5) }\end{array}$ & $\begin{array}{c}2 \cdot 0 \\
(\operatorname{sheep~6)}\end{array}$ & $\begin{array}{c}8 \cdot 0 \\
\text { (sheep } 7)\end{array}$ \\
\hline ted bile acids & 536 & 993 & 2367 \\
\hline lipids & 128 & I I I & I68 \\
\hline $\begin{array}{l}\text { ified fatty acids } \\
\text { lipids }\end{array}$ & I38 & 179 & 85 \\
\hline hatidylcholine & 28 & 19 & None \\
\hline hosphatidylcholine & Io & 37 & None \\
\hline & $4 \cdot 0$ & $5 \cdot 2$ & $8 \cdot 0$ \\
\hline
\end{tabular}

Details of the sampling procedure are given on p. 240 .

Table 7. Analyses of liquid (micellar) phase of jejunal contents obtained from two cannulated sheep

\begin{tabular}{|c|c|c|c|c|}
\hline \multirow[b]{2}{*}{ Animal } & \multirow[b]{2}{*}{ Constituent } & \multirow{2}{*}{$\begin{array}{l}\text { Amount (mg) } \\
\text { in liquid } \\
\text { phase from } \\
\text { roo ml } \\
\text { digesta }\end{array}$} & \multicolumn{2}{|c|}{$\begin{array}{l}\% \text { of total amount in whole } \\
\text { digesta* associated with }\end{array}$} \\
\hline & & & $\begin{array}{l}\text { Liquid } \\
\text { (micellar) } \\
\text { phase }\end{array}$ & $\begin{array}{c}\text { Solid } \\
\text { matter } \\
\text { (by difference) }\end{array}$ \\
\hline Sheep 6 & $\begin{array}{l}\text { Conjugated bile acids } \\
\text { Unesterified fatty acids } \\
\text { Phosphatidylcholine } \\
\text { Lysophosphatidylcholine }\end{array}$ & $\begin{array}{r}606 \\
12 \\
5 \\
14\end{array}$ & $\begin{array}{r}6 x \\
7 \\
26 \\
38\end{array}$ & $\begin{array}{l}39 \\
93 \\
74 \\
62\end{array}$ \\
\hline Sheep 7 & $\begin{array}{l}\text { Conjugated bile acids } \\
\text { Unesterified fatty acids }\end{array}$ & $\begin{array}{r}1372 \\
7\end{array}$ & $\begin{array}{r}58 \\
8\end{array}$ & $\begin{array}{l}42 \\
92\end{array}$ \\
\hline
\end{tabular}

observations are consistent with the occurrence of this process in the intestinal lumen. Though the absorption of intact phosphatidylcholine is not precluded, it seems reasonable to suppose that the absence of phosphatidylcholine and lysophosphatidylcholine from the digesta obtained from sheep 7 was probably largely the result of the complete uptake and/or dissimilation of the lyso compound originally present in bile or derived enzymically from the phosphatidylcholine of bile. In this connexion it is relevant to note that Nilsson \& Borgström (1967) found that, whereas phosphatidyl- 
choline was not absorbed by intestinal slices of hamsters and rats, lysophosphatidylcholine was readily assimilated and acylated.

Recent work (reviewed by Senior (1964) and Hofmann (1966)) on the digestion of lipids in non-ruminant animals has indicated that the mucosal uptake of long-chain fatty acids from the intestinal lumen is dependent on their being rendered soluble in the form of mixed micelles with conjugated bile acids. This solubilization of fatty acids in bile acid micelles is promoted by (I) the presence of monoglycerides which expand the micellar structure and (2) partial ionization of the fatty acids which occurs when the $\mathrm{pH}$ of the lumen contents reaches a value of about 6.5. It was thus of interest to examine the nature and amounts of the water-soluble (micellar) constituents of the jejunal digesta of the sheep since, as already mentioned, complete lipolysis of ingested glyceridic lipids takes place in the rumen and the liberated glycerol is fermented. Unesterified fatty acids thus predominate in the lipids entering the small intestine and, as shown by Bath \& Hill ( 1967$)$, very little, if any, monoglyceride is present.

The results of the analyses given in Table 7 show that, at $\mathrm{pH} 5 \cdot 2$ in the upper jejunal sample from sheep 6 , only a small part $(7 \%)$ of the unesterified fatty acids was present in solution, together with $26 \%$ of the phosphatidylcholine and $38 \%$ of the lysophosphatidylcholine; the latter, like monoglyceride in the chyme of non-ruminants, may facilitate the micellar solubilization of fatty acids. In addition to most of the lipid, a considerable proportion ( $39 \%$ ) of the conjugated bile acids was associated with the particulate matter of the digesta, presumably as a result of having been precipitated from solution in bile by the low $\mathrm{pH}$ conditions obtaining in the upper jejunum. In this context it is of interest to note that very recently Eastwood \& Boyd (I967) have reported that, in the lumen of the small intestine of the rat, bile acids are distributed between the solid and aqueous phases of the digesta.

Though the sample of digesta from sheep 7 was alkaline ( $\mathrm{pH} 8 \cdot 0$ ) and, owing to the absorption of water, more concentrated than that from sheep 6 , a similar proportion of the total bile acids was present in the solid phase. The unesterified fatty acid content of the digesta from sheep 7 was only about half that in the sample from sheep 6 (Table 6) and yet, despite the alkalinity of the medium, the proportion in micellar solution was of a similar low order.

The conditions which influence the distribution of bile acids and lipids between the solid and liquid phases of intestinal contents are evidently complex and remain to be investigated in detail. Nevertheless, it is evident that only a small fraction of the total fatty acids is available at any given time for absorption in micellar form though, as the following paper (Lennox \& Garton, I968) shows, up to $500 \mathrm{mg}$ fatty acids/h can be absorbed, presumably in micellar form, from a diet of dried grass or one of hay and vegetable concentrates.

We wish to thank our colleagues, Miss Rosa M. Campbell, Dr R. N. B. Kay and Dr D. Scott, who kindly made available to us the sheep which were used in these studies. 


\section{REFERENCES}

Adams, E. P. \& Heath, T. J. (1963). Biochim. biophys. Acta 70, 88.

Ash, R. W. (1962). Anim. Prod. 4, 309.

Bath, I. H. \& Hill, K. J. (1967). F. agric. Sci., Camb. 68, 139.

Bligh, E. G. \& Dyer, W. J. (1959). Can. F. Biochem. Physiol. 37, 911.

De Haas, G. H. \& Van Deenen, L. L. M. (1965). Biochim. biophys. Acta 106, 315.

Dole, V. P., James, A. T., Webb, J. P. W., Rizack, M. A. \& Sturman, M. F. (1959). F. clin. Invest. 38, I 544 .

Duncan, W. R. H. \& Garton, G. A. (1962). F. Lipid Res. 3, 53.

Duncan, W. R. H. \& Garton, G. A. (1963). Biochem. F. 89, 414.

Eastwood, M. A. \& Boyd, G. S. (1967). Biochim. biophys. Acta 137, 393.

Feliński, L., Garton, G. A., Lough, A. K. \& Phillipson, A. T. (1964). Biochem. F. 9o, I 54.

Garton, G. A. (1965). In Physiology of Digestion in the Ruminant, p. 390. [R. W. Dougherty, editor.] Washington, DC.: Butterworths.

Garton, G. A. (1967). Wld Rev. Nutr. Diet. 7, 225.

Garton, G. A. \& Duncan, W. R. H. (1957). Biochem. F. 67, 340.

Garton, G. A., Duncan, W. R. H. \& Lough, A. K. (r96I). Biochim. biophys. Acta 47, 592.

Hofmann, A. F. (1964). In New Biochemical Separations, p. 266. [A. T. James and L. J. Morris, editors]. London: D. Van Nostrand Co. Ltd.

Hofmann, A. F. (1966). Gastroenterology 50, 56.

Leat, W. M. F. (1965). Biochem. F. 94, 2 IP.

Lennox, A. M. \& Garton, G. A. (1968). Br. $\mathcal{F}$. Nutr. 22, 247.

Lennox, A. M., Lough, A. K. \& Garton, G. A. (1965). Biochem. \%. 96, 27P.

Long, C. \& Penny, I. F. (1957). Biochem. F. 65, 382 .

Malins, D. C. \& Mangold, H. K. (1960). F. Am. Oil Chem. Soc. 37, 576.

McCarthy, R. D. (1962). In Use of Radioisotopes in Animal Biology and the Medical Sciences. Vol. 2, p. 151. London and New York: Academic Press Inc.

Nilsson, A. \& Borgström, B. (1967). Biochim. biophys. Acta 137, 240.

Senior, J. R. (1 964). F. Lipid Res. 5, 495.

Slotboom, A. J., De Haas, G. H. \& Van Deenen, L. L. M. (1963). Recl. Trav. chim. Pays-Bas Belg. 82, 469 .

Van den Bosch, H. \& Van Deenen, L. L. M. (1965). Biochim. biophys. Acta 106, 326.

Wagner, H., Hörhammer, L. \& Wolff, P. (I96r). Biochem. Z. 334, I75.

Ward, P. F. V., Scott, T. W. \& Dawson, R. M. C. (1964). Biochem. F. 92, 60. 